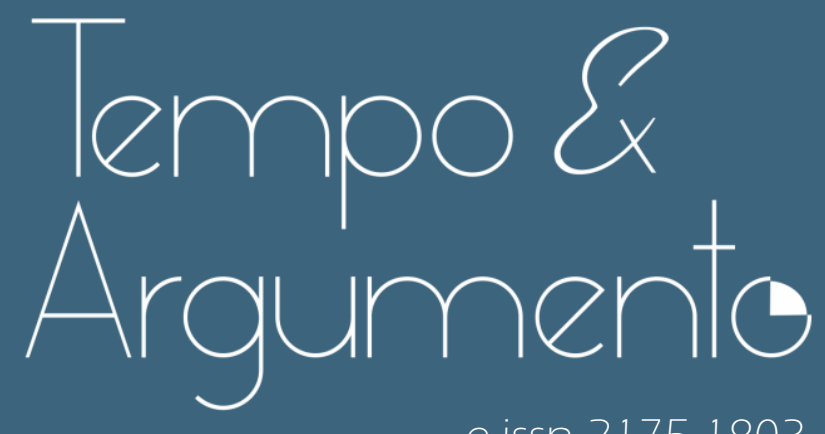

e-issn 2175-1803

Los curas villeros en la Argentina actual: entre la herencia católica tercermundista y el Papa

Francisco

- Claudia Touris

Doctora en Historia. Profesora de la Universidad de Buenos Aires (UBA) y de la

Universidad Nacional de Luján (UNLU)

Buenos Aires - ARGENTINA

ctouris@gmail.com

(D) orcid.org/0000-0002-4041-1344

Para citar este articulo (ABNT):

TOURIS, Claudia. Los curas villeros en la Argentina actual: entre la herencia católica tercermundista y el Papa Francisco. Tempo e Argumento, Florianópolis, e0 108 ,

2021. Número especial.

doi http://dx.doi.org/10.5965/21751803ne2021 e0108 


\title{
Los curas villeros en la Argentina actual: entre la herencia católica tercermundista y el Papa Francisco
}

\begin{abstract}
Resumen
Este artículo pretende contribuir a la discusión sobre la trayectoria de los colectivos sacerdotales en América Latina, particularmente de Argentina, desde una perspectiva histórica que tome en cuenta las relaciones de continuidad y de ruptura entre el Movimiento de Sacerdotes para el Tercer Mundo (MSTM), que actuó activamente entre fines de los años 1960 y mediados de los años 1970, y el grupo de curas villeros actuales que se referencia en la figura del Papa Francisco. Nos interesa dar cuenta de un recorrido comparativo entre sus opciones pastorales, eclesiales y políticas y su filiación teológica. Se trata de una investigación que retoma los planteos de mi pesquisa doctoral sobre la "constelación tercermundista" en la Argentina, demostrando que dicha constelación recibió el influjo teológico de la Pastoral Popular - Teología del Pueblo (TP), que fue la versión argentina de la Teología de la Liberación $(T L)$, pero en clave culturalista en vez de clasista y con elementos más cercanos al paternalismo clerical y a prácticas populistas, donde confluyeron la "opción preferencial por los pobres" y la "opción por el peronismo". Lejos de haber perecido, esta corriente se manifiesta en la actualidad en los postulados del Papa Francisco y los curas villeros de la Ciudad de Buenos Aires. Nuestra metodología de trabajo es preferentemente de tipo cualitativo y se nutre de bibliografía especializada en el tema, documentos eclesiásticos, libros teológicos, entrevistas orales, y análisis de artículos de prensa escrita y fuentes audiovisuales.
\end{abstract}

Palabras clave: curas villeros; curas tercermundistas; teología del Pueblo; Papa Francisco; populismo.

\section{Slum priests in present-day Argentina: between the Third World Catholic heritage and Pope Francis}

\begin{abstract}
This article aims to contribute to the discussion on the history of priestly groups in Latin America, particularly in Argentina, from a historical perspective that takes into account the relations of continuity and rupture between the Movement of Priests for the Third World (Movimiento de Sacerdotes para el Tercer Mundo [MSTM]), which operated actively between the late 1960s and mid-1970s, and the group of current slum priests referred to in the figure of Pope Francis. We are interested in giving an account of a comparative journey between his pastoral, ecclesial, and political options and his theological affiliation. This is an examination that takes up the proposals of my doctoral research study on the 'Third World constellation' in Argentina, showing that such a constellation received the theological influence of the Popular Pastoral or Theology of the People (TP), which was the Argentine version of Liberation Theology (LT), but in a culturalist rather than classist key and with elements closer to clerical paternalism and populist practices, where the 'preferential option for the poor' and the 'option for Peronism' converged. Far from having perished, this current is currently manifested in the postulates of Pope Francis and the slum priests in the City of Buenos Aires. Our work methodology has preferably a qualitative nature and it is supported by specialized bibliography on the theme, ecclesiastical documents, theological books, oral interviews, and analysis of written press articles and audiovisual sources.
\end{abstract}

Keywords: slum priests; third world priests; theology of the people; Pope Francis; populism. 


\section{Introducción}

Los curas villeros son un colectivo sacerdotal argentino existente desde 1998 que se caracteriza por su trabajo socio-pastoral en las villas miseria de la Ciudad de Buenos Aires. Su labor fue favorecida por el entonces arzobispo de Buenos Aires y luego cardenal, Jorge Mario Bergoglio. Sin embargo, este grupo se reconoce heredero de los curas villeros que en los años 1970 formaron parte del Movimiento de Sacerdotes para el Tercer Mundo (MSTM), que se desarrolló entre 1967 y 1973 y que tuvo una estrecha relación con el peronismo a nivel político y con la Teología del Pueblo (TP) a nivel teológico y eclesial. Su referente principal fue el sacerdote Carlos Mugica, asesinado en 1974 por la Triple A'. Los curas villeros actuales se referencian a su vez en la figura del Padre José María Di Paola, más conocido como el "Padre Pepe". Aunque de manera superficial algunos adherentes a esta corriente del catolicismo popular consideren de que se trata de un grupo progresista y que levanta los mismos postulados que sus predecesores, consideramos que la realidad es más compleja, puesto que el grupo actual carece de las aristas contestarías que tuvieron los curas villeros pioneros. Por último, ni unos ni otros pertenecieron sin más a la línea de la Teología de la Liberación (TL), que predominó en otros países latinoamericanos como Brasil, sino que al igual que el Papa Francisco se inscriben en un linaje creyente de corte clerical, paternalista y populista.

\section{Los pioneros tercermundistas}

Entre 1967 y 1973, cobró protagonismo en la escena pública argentina un colectivo sacerdotal inspirado en el Mensaje de los 18 Obispos del Tercer Mundo² que fue denominado MSTM. En el marco de la dictadura de la revolución argentina (1966-1973), estos sacerdotes, que también adhirieron a los postulados

\footnotetext{
${ }^{1}$ La Triple A (Alianza Anticomunista Argentina) fue una organización de extrema derecha organizada por el ministro de Bienestar Social, José López Rega, entre 1973 y 1975, durante el tercer gobierno peronista. Se trató de un grupo parapolicial que amedrentó, persiguió y asesinó a decenas de militantes de izquierda, principalmente artistas, estudiantes, intelectuales, sindicalistas y políticos.

${ }^{2}$ Fue un documento firmado por 18 obispos de América, Asia y África a iniciativa del arzobispo de Olinda y Recife, Hélder Câmara, el 15 de agosto de 1967, con el propósito de aplicar en sus regiones la Encíclica Populorum Progressio a la vez que afirmó la compatibilidad del cristianismo y del socialismo.
} 
de Medellín (1968) y la "opción por los pobres", se sumaron a la ola de contestación social que irrumpió con el Cordobazo (1969)³, el fenómeno insurreccional (aparición de las organizaciones armadas) y el clima de revuelta cultural que impregnó a toda la Nueva Izquierda. En el caso del catolicismo latinoamericano el Concilio Vaticano II -1962-1965- aceleró cambios que se venían anunciando en las diferentes iglesias nacionales y en poco tiempo la Teología del Desarrollo (TD) fue desplazada por la TL, a través de textos novedosos escritos por teólogos latinoamericanos que habían pasado por universidades europeas, pero que, a diferencia de otros momentos históricos, pusieron el acento en las singularidades de una región caracterizada por su pobreza estructural y una situación de "violencia institucionalizada" que exigía un compromiso radical de parte de los cristianos. En la práctica, esto conllevaba convertirse en actores sociales y políticos que acompañaran y animaran el proceso revolucionario en el que parecía haber entrado América Latina, al calor del ejemplo de la Revolución Cubana ${ }^{4}$.

Si bien el MSTM fue un movimiento exclusivamente sacerdotal,

[...] el influjo de dichos clérigos trascendió los ámbitos intelectuales de formación católica, o de las parroquias, y su presencia fue muy importante en ambientes populares como barrios, villas de emergencias, fábricas y sindicatos, al mismo tiempo que actuaban como asesores de los estudiantes secundarios y universitarios. (TOURIS, 2010, p. 132)

Esta diversidad de ámbitos de sociabilidad por la que transitaron los Sacerdotes para el Tercer Mundo fue una de las principales causas que posibilitaron la conformación de una red laxa y heterogénea de actores religiosos,

\footnotetext{
${ }^{3}$ Fue una insurrección popular ocurrida en la Ciudad de Córdoba, entre el 29 y 30 de mayo de 1969. Fue liderada por sindicalistas opositores al gobierno, pertenecientes a la CGT de los argentinos. La participación obrero-estudiantil fue su signo más distintivo y a partir de allí se produjeron varios levantamientos populares que llevaron a la caída del dictador Onganía y debilitaron a los gobiernos de la revolución argentina.

${ }^{4}$ Entre los textos pioneros que permitieron el desarrollo de la TL podemos mencionar los libros de: Gustavo Gutiérrez. Teología de la Liberación. Perspectivas (1971); Hugo Assmann. Teología desde la praxis de la liberación (1973); Leonardo Boff. Jesucristo, el liberador. Ensayo de cristología Crítica para nuestro tiempo (1974).

Para el estudio de la Teología de la Liberación desde un punto de vista académico, existe una nutrida bibliografía de la que nos interesa mencionar los trabajos de Christian Smith. La Teología de la Liberación. Radicalismo religioso y compromiso social (1994); y el de Michael Löwy. Guerra de Dioses. Religión y política en América Latina (1999).
} 
sociales y políticos que hemos denominado la "constelación tercermundista" (TOURIS, 2021) y que estuvo integrada por sacerdotes, religiosos, "monjas", laicos de las ramas especializadas de la Acción Católica - AC, alfabetizadores populares, catequistas, profesionales de universidades públicas y confesionales, así como cristianos de izquierda (Grupo de Cristianismo y Revolución)5. Estos últimos, mayoritariamente jóvenes, se tornarían más radicalizados y emigrarían pronto hacia agrupaciones armadas que los alejarían bastante del trabajo de base propio de la mayor parte de la "constelación tercermundista". En esta amplia “constelación tercermundista” se destacaron los curas villeros. En septiembre de 1969, nació formalmente el Equipo Pastoral de Villas a instancias del arzobispo Juan Carlos Aramburu. Estuvo formado inicialmente por Héctor Botán, Jorge Vernazza, Manuel Pérez Vila, Carlos Mugica, Rodolfo Richiardelli, Jorge Goñi y José María Meiseigeier. Este equipo sacerdotal se integró a las diferentes villas que existían en ese entonces en la Ciudad de Buenos Aires y llevó adelante una serie de actividades específicas en cada territorio y otras coordinadas en el marco del grupo. Se trataba sobre todo de tareas de promoción social y asistencia pastoral, estimulando la iniciativa de los pobladores de las villas para reclamar y hacer escuchar sus peticiones ante un estado municipal y nacional que oscilaba entre políticas asistencialistas o de erradicación de las villas miseria.

Cabe señalar que el MSTM llegó a albergar a casi el 10\% de del clero argentino, tuvo un perfil predominantemente diocesano y un rango etario entre los 30 y los 40 años de edad. En su primera etapa acentuaron el rol profético de la función sacerdotal lo cual los llevó a hacer denuncias públicas contra la dictadura del general Juan Carlos Onganía, organizar marchas, ollas populares, acompañar huelgas obreras y estudiantiles, realizar huelgas de hambre y a no celebrar misas navideñas por considerar que no se vivía en una sociedad donde predominaran los valores cristianos humanitarios y solidarios. Más tarde, la dinámica política los condujo a sentirse atraídos por la "opción peronista”, que interpretaron como la "opción por los pobres" en clave argentina. Consideraron

\footnotetext{
Se trató de una revista dirigida por el ex seminarista Juan García Elorrio que se basó en los postulados del Concilio Vaticano II, pero después se radicalizó y tomó como propias las ideas de Camilo Torres, privilegiando pues los diagnósticos insurreccionales. Este grupo estuvo vinculado a los orígenes de la agrupación guerrillera Montoneros, que se autodenominará peronista.
} 
que el peronismo era el sustrato de un cristianismo verdadero. Así justificaba Carlos Mugica (1973) por qué la Iglesia Católica debía acercarse al peronismo en un contexto que impelía a cambiar las estructuras injustas:

La acción de la Iglesia debe estar orientada hacia el pueblo, pero también desde el pueblo mismo. Y creo que esto es fundamental para hacer una valoración del peronismo. Porque una cosa es mirar al peronismo desde los pobres, desde el pueblo, y otra cosa es mirarlo desde la clase media o desde la oligarquía. (MUGICA, 1973, p. 20)

De alguna manera asimilaba la mutación que le exigía a la Iglesia toda a partir de su propio proceso de "conversión”, dado que él pertenecía a una familia burguesa de filiación antiperonista.

La Iglesia es de todos pero ante todo es de los pobres [...] seguir a Cristo es hacer como Cristo. Implica una opción concreta de ese hacer y toda opción concreta está cargada de historicidad y por lo tanto es relativa [...] los valores cristianos son propios de cualquier época, trascienden los movimientos políticos, en cambio el peronismo es un movimiento que asume los valores cristianos en determinada época. La opción política es el peronismo. Esto no significa que no se puede ser cristiano y no peronista. Lo que sí me parece más difícil es ser cristiano y antiperonista. (MUGICA, 197, p. 23-24)

A partir de 1969, una de las acciones más importantes de los curas villeros fueron las peregrinaciones a Luján. En ellas se combinaban la denuncia de injusticias con la declaración de necesidades (construcción y créditos para viviendas, obras sanitarias, conexiones de energía eléctrica, reparación de calles, etc.). Asimismo,

[...] el apego de los pobladores a ciertas manifestaciones de una religiosidad popular más focalizada en el rito y en una concepción más tradicional del rol sacerdotal, llevó a los curas villeros a revalorizar estos elementos que ellos mismos habían subestimado. De ahí que la concepción teológico-pastoral que abrazaron buena parte de ellos fuera la línea de la Teología del Pueblo o Pastoral Popular enunciada por Lucio Gera y Rafael Tello. Esta línea que pervive en la actualidad puede ser considerada como una de las corrientes de la Teología de la Liberación. Se caracterizó por su opción por los pobres identificados con la categoría de pueblo entendido sobre todo como una categoría identitaria de raíz cultural más que de clase. (TOURIS, 2013, p. 9) 
La vigencia del Gran Acuerdo Nacional (GAN) -1971- y la posibilidad del regreso de Perón -1972- favorecieron la creación de nuevas organizaciones peronistas, como el Frente Villero de Liberación Nacional (FVPLN) y el Movimiento Villero Peronista (MVP), capaces de gestionar las demandas y conseguir fondos para sus propios emprendimientos. Durante el breve gobierno de Héctor Cámpora, las villas vivieron un momento de efervescencia social y política. El referente más conocido de los curas villeros, Carlos Mugica -que actuaba en la Villa 31 del barrio de Retiro- aceptó un cargo ad honorem como asesor en el Ministerio de Bienestar Social dirigido por José López Rega (líder de la ultraderecha peronista, creador de la Triple A y responsable intelectual de cientos de asesinatos políticos que tuvieron como blanco principal a los militantes de la Tendencia Revolucionaria del peronismo). Sin embargo, la fractura entre las diferentes vertientes del peronismo repercutió directamente dentro del MSTM. La ruptura de Juan Domingo Perón con Montoneros (1 de mayo de 1974) se expresó en la división de la Juventud Peronista (JP) entre la JP Regionales (de la Tendencia Revolucionaria) y la JP Lealtad (lealtad hacia Perón): los curas villeros privilegiaron la lealtad del "pueblo" hacia Perón y criticaron la posición de "vanguardia" asumida por el sector de la izquierda peronista, que se identificaba con Montoneros. Esta situación sumada al asesinato de Mugica (11 de mayo de 1974) y la muerte de Perón (1 de julio de 1974) los llevaron a un repliegue cada vez más sacramentalista en lo eclesial y más conservador en lo político, ya que el gobierno de Isabel Perón (1974-1976) se caracterizó por su derechización a nivel político, social y económico. Por su parte, las bases villeras también resultaron debilitadas y divididas por estos enfrentamientos y consternadas por la trágica muerte de su mayor protector, el sacerdote Carlos Mugica, acribillado a balazos al salir de oficiar misa en la parroquia de San Francisco Solano. Miles de personas desfilaron ante su féretro, primero en la parroquia de San Francisco Solano y luego en la capilla de Cristo Obrero en la Villa 31. Por último, una impresionantes multitud de representativa de todas las clases sociales acompañó el cortejo fúnebre a lo largo de la Avenida Callao hasta llegar al Cementerio de La Recoleta.

Poco tiempo después, el golpe cívico-militar perpetrado el 24 de marzo de 1976 instauró un nuevo orden de terror y persecución hacia los sectores que 
formaban parte de la "constelación tercermundista”, que tendría numerosas víctimas entre sus filas.

\section{Los herederos: los curas villeros del Papa Francisco}

A fines de la década de 1990, el tema de la exclusión social y la pobreza estructural que afectaba duramente a los sectores populares tras casi una década de recetas económicas neoliberales impulsadas por los gobiernos de Carlos Menem y de Fernando de la Rúa sucesivamente provocaron que la voz de la jerarquía eclesiástica se hiciera sentir más potente. Entre los prelados preocupados por la situación social se destacó el arzobispo de Buenos Aires, Jorge Bergoglio, quien decidió revitalizar la Pastoral de Villas de Emergencia, agrupando formalmente en ella desde 1998 a curas jóvenes que vivían o realizaban su trabajo en esos territorios. Ese grupo de sacerdotes fue el germen de la nueva generación de curas villeros, muy activos en la actualidad.

¿Qué hay de nuevo y cuánto de renovación en los curas villeros actuales respecto de sus antecesores tercermundistas? ¿En qué medida influye la mediación de Bergoglio devenido Papa Francisco desde 2013? ¿Es acaso la TP la que inspira los "gestos" del Papa Francisco?

Sin duda, el apoyo de Bergoglio fue decisivo para que la pastoral de Villas de Emergencia se difundiera a partir de poder contar con mayor apoyo institucional, tanto en un sentido material como simbólico. Más sacerdotes del clero de Buenos Aires fueron destinados a los asentamientos, así como también se les proporcionó más recursos para sus actividades.

La Villa 21-24 de Barracas y el Núcleo habitacional Zabaleta albergaban hacia 2013 un número de 45.000 personas, la Villa 1-11-14 del Bajo Flores unas 40.000 personas, la Villa 31 de Retiro, 30.000 personas. Además, La Iglesia extendió su presencia a la Villa 20 del barrio de Lugano, la Villa 15, conocida como Ciudad Oculta, la Villa 3 del barrio Ramón Carrillo, la Villa Rodrigo Bueno, formada en torno al exclusivo barrio de Puerto Madero, la Villa 6, en el barrio de Cildáñez, la Villa 19 del barrio INTA, y la Villa 26, del barrio del Riachuelo. Fue así que de un número inicial de 8 sacerdotes se pasó a 22 sacerdotes a partir de 1998, y ya 
hacia 2019 el equipo de curas villeros de la ciudad extendió su presencia desde 11 barrios porteños a otros ubicados en villas bonaerenses de los partidos de San Martín, San Isidro, La Matanza, Moreno, Lomas de Zamora y Quilmes. Las tareas de los curas villeros, además de las propiamente religiosas, son básicamente de prevención, formación y asistencia: llevan adelante comedores, talleres de oficio, actividades deportivas y recreativas con jóvenes y asistencia informal de los más diversos tipos. El acuciante problema del consumo de drogas, principalmente de "paco" (una droga de bajo costo y muy perjudicial elaborada a partir de los residuos de cocaína), la marginalidad, el delito y la violencia de género ha llevado a la creación de los Hogares de Cristo, que, según Silvina Premat, se multiplicaron muy rápidamente, llegando a un número aproximado de 200 en toda la Argentina (PREMAT, 2010). Estos hogares se orientan a incluir y acompañar integralmente a toxicómanos.

Si bien al igual que sus pares de los 1970, el grupo de curas villeros actuales es un cuerpo colegiado, hay 2 figuras sobresalientes. Una es Gustavo Carrara, ascendido a obispo y que está a cargo de lo que oficialmente se llama Equipo para la Pastoral en las villas de Capital y Gran Buenos Aires. La otra figura es José María Di Paola, el "Padre Pepe", muy mediático luego de que los narcotraficantes lo amenazaran de muerte, siendo párroco de la Virgen de los Milagros de Caacupé en la Villa 21-24 de Barracas, de donde tuvo que irse en 2009. Este episodio fue conocido públicamente por la denuncia del propio cardenal Bergoglio en una misa celebrada en la catedral metropolitana, lo cual contribuyó a difundir los que sucedía con el problema de la droga, la trata de personas y el trabajo esclavo. A partir de este hecho, el 3 de abril de 2009 los curas villeros dieron a conocer un documento sobre las drogas:

Queremos en este momento tener presentes a nuestros predecesores y maestros en la fe. Hoy seguimos su fidelidad al Evangelio de Jesús en la Iglesia en nuestro compromiso en las villas de Buenos Aires con los desafíos de esta época, en las mismas villas donde trabajaron nuestros maestros y donde han dado la vida día a día en el martirio y en compromiso con los más pobres. Por eso vamos a presentar las velas que representan la luz que iluminó sus vidas en nuestras villas. Ahora ellos nos iluminan desde el cielo. (PREMAT, 2010, p. 35) 
Durante su prédica el "Padre Pepe" hizo encender una vela para cada uno de los 7 curas villeros que los precedieron en su trabajo pastoral en las villas, refiriéndose particularmente a Mugica como "nuestro mártir".

Con posterioridad a esta amenaza de muerte, el "Padre Pepe" prosiguió su trabajo pastoral en el paraje de Campo Gallo, provincia de Santiago del Estero, y desde 2012 en la Villa de la Cárcova, diócesis de San Martín, en el conurbano bonaerense, uno de los lugares con más villas y asentamientos del país. Este sacerdote es, sin duda, el que tiene un diálogo más cercano con el Papa Francisco y ha viajado al exterior incluso para dar testimonio del diálogo interreligioso que ya Bergoglio fomentaba en Buenos Aires.

Los curas villeros se reúnen para analizar sus experiencias pastorales cuyas conclusiones se suelen dar a conocer en documentos públicos como lo hacía el MSTM y también ante situaciones específicas (como fue el tema de la droga, el debate sobre el aborto y el encuentro con Alberto Fernández tras las elecciones presidenciales primarias de 2019). Otras instancias significativas son las reuniones conmemorativas que realizan dos veces por año en la capilla Cristo Obrero: una para el aniversario del fallecimiento de Mugica y la otra para la peregrinación a Luján que se realizan, desde 1969, el domingo previo a Navidad (PREMAT, 2010).

Consideramos que la práctica conmemorativa de las figuras del panteón de mártires tercermundistas ha sido incorporada por Bergoglio por primera vez y un poco a contrapelo de cierto sector de la jerarquía eclesiástica argentina, ya que fue el primer alto prelado en honrar la memoria de monseñor Angelelli, obispo de La Rioja asesinado en 1976, presidir las misas en memoria de los padres palotinos asesinados también en 1976 en la Ciudad de Buenos Aires y, finalmente, decidir el traslado de los restos de Mugica (1999) desde el Cementerio de la Recoleta a la Villa 31, donde se encuentran en la actualidad. Esta "operación memorialística" en clave tercermundista se explica tanto desde la lógica institucional católica que tiende a incorporar paulatinamente figuras que otrora resultaron incómodas, así como también por la clara intención de revertir una narrativa propia sobre su actuación durante la última dictadura que lo ubicaba en un lugar controversial a partir del caso de los dos jesuitas: (Orlando Yorio y 
Francisco Jalics) secuestrados por la Marina mientras Bergoglio era Provincial de la Compañía de Jesús en la Argentina (TOURIS, 2015).

Una operación memorialística similar se observa en lo que fue la beatificación (2015) y canonización de monseñor Óscar Arnulfo Romero (2018), convertido en "San Romero de América" a la vez que desde que asumió el pontificado buscó un reacercamiento a los teólogos de la liberación que habían sido perseguidos en la etapa de Juan Pablo II y Benedicto XVI. Sin embargo, no debemos confundirnos, ya que estos hechos no significan una adhesión del Papa Francisco a los postulados de la TL, ni mucho menos que sea esta tradición teológica la que inspire de todos sus actos como pretenden denunciar los sectores conservadores y tradicionalistas o como anhelan los liberacionistas.

En cuanto a la cuestión teológica, hemos adelantado que la TL que se desarrolló ampliamente en América Latina tomó forma propia en Argentina a través de la TP. Más que apoyarse en los planteos y los libros de Gustavo Gutiérrez o Leonardo Boff, la TP recurría a teólogos argentinos, como Lucio Gera y Rafael Tello. Los curas villeros adoptaron fuertemente las propuestas de Tello en lo concerniente a la valoración positiva de la religiosidad popular, las peregrinaciones juveniles y las peregrinaciones villeras al santuario de Luján, la exaltación de las devociones marianas y el culto a los santos como San Cayetano. La apelación al "pueblo" fue más importante que la incitación a la lucha de clases y otras perspectivas provenientes del marxismo. Se trató de una teología que leía la historia argentina y latinoamericana en clave nacionalista e hispanista y, por ende, tenía un filón antiliberal y antimoderno muy marcado. Se consideraba que el pueblo era portador de un saber teologal, inexistente en las clases medias y altas. Precisamente en el corazón de ese pueblo estaban los oprimidos, los pobres, los elegidos por Dios ${ }^{6}$. Esta "sensibilidad antiburguesa" atravesó a toda la "constelación tercermundista” y se proyectó hacia el presente de los curas villeros que en la actualidad casi no mencionan a la TL ni sus conceptos más revulsivos. Sí, en cambio, en más de una ocasión hablan de la TP y sus referentes, "los grandes maestros", según el "Padre Pepe".

\footnotetext{
${ }^{6}$ Para entender el desarrollo de la TP o Pastoral Popular se destaca el libro pionero de Sebastián Politi (1992) y el posterior análisis de Marcelo González (2005).
} 
Uno de los documentos de los curas villeros donde mejor se expresa esta concepción es "Reflexiones sobre la urbanización y el respeto de la cultura villera”, que señala, entre otras cosas, que

[...] la villa no es un lugar solo para ayudar, es más bien el ámbito que nos enseña una vida más humana y, por consiguiente, más cristiana. Valoramos la cultura que se da en la villa, surgida del encuentro de los valores más nobles y propios del interior del país o de los países vecinos, con la realidad urbana. (REFLEXIONES, 2007, p. 2)

En ese documento se contraponen los valores evangélicos de la villa a los defendidos por la sociedad liberal y sus expresiones de derecha y de izquierda. También monseñor Carrara afirmó que:

La Teología del Pueblo se basa en la sabiduría popular, no en categorías o diagnósticos que se imponen desde arriba. Se la puede pensar, dicen los sacerdotes, como una hermenéutica del pueblo pobre, escaso de riqueza pero no de saber. Las ideas se alimentan, bajo este paradigma, de la vida: "Aquí no existe izquierda o derecha, existe querer tener agua, luz, vivir mejor" (DI MARCO, 2010)

En una perspectiva afín, aunque más ligada al diferente contexto sociopolítico en que les toca vivir a los curas villeros de la actualidad con relación al de sus antecesores, el "Padre Pepe" afirmó también que

[...] los setenta eran tiempos de incomprensión, pero hoy, corrida la ideología, todo está más claro [...] Los desafíos son acordes a este momento: hoy lidiamos con la violencia del delito y de la droga, y no con la de la política. Son desafíos nuevos, pero el espíritu es el mismo (DI MARCO, 2010)

Ese "espíritu" del que habla el "Padre Pepe" implica para él y sus pares un profundo compromiso social con los sectores más desprotegidos y se expresa en términos que buscan la integración con la sociedad más que la confrontación contra un orden injusto. He aquí una diferencia fundamental con los curas villeros pioneros que creían y luchaban por un proyecto de emancipación social y política y pretendían que los habitantes de las villas fueran artífices de su propia “liberación”. Por eso, para el "Padre Pepe" un pobre no es la víctima de un sistema de explotación, sino "una persona que no puede acceder al trabajo digno"; el 
problema de los políticos no es que sean los responsables de un sistema clientelar con respecto a los pobres, sino su carencia de sensibilidad social y su "falta de calle"; y, en todo caso, no existiría "un odio de clase" hacia los villeros, sino más bien "un problema de integración de las villas" (MANO, 2020).

De esta búsqueda de asistencia social, integración y mejora de las condiciones de vida -que los curas villeros asocian principalmente a la necesidad de una mayor presencia del Estado- se explica que no se expresen en términos de clase o ni se animen a definiciones partidarias o ideológicas más claras. Por ejemplo, en una entrevista televisiva donde se le preguntaba sobre su preferencia política decía el "Padre Pepe":

Si me llamaran por teléfono Macri o Cristina, les diría lo mismo: que le presten atención a los pobres [...]. La grieta no es entre conservadores y progresistas, la grieta es la del 30\% que está en la pobreza [...]. Tenemos un pensamiento muy libre. Nuestro compromiso es con la Iglesia y con la gente. Nunca nos ligamos a ninguna mirada política.

No obstante estos dichos, sus definiciones políticas están presentes en sus posiciones antiliberales y antimodernas propias de la TP. Señaló además que estaba claro que los curas villeros no iban a apoyar al capitalismo salvaje que supuestamente representaba el entonces presidente Mauricio Macri, que, según el "Padre Pepe", era parte de ese capitalismo salvaje, al decir "es bastante capitalista" (DI PAOLA, 2018).

Silvina Premat subraya, a su vez, que al visitar el despacho del "Padre Pepe" puede advertirse una pared llena de fotos donde aparecen la del Padre Mugica, la de Bergoglio y la de Perón (PREMAT, 2010), que evidentemente reflejan su identificación eclesial y política. Por último, cabe destacar que, en un programa de radio de filiación peronista, el sacerdote declaró que en la Argentina "tuvimos una época de oro entre el 45 y el 55, con pleno empleo, industria nacional y pensamiento doctrinario, filosófico y espiritual muy profundo" (PADRE, 2020), haciendo alusión obviamente a los dos primeros gobiernos de Perón (1946-1955), donde se implementaron políticas compatibles con un estado benefactor que favoreció a las clases asalariadas medias y obreras. 
Podemos suponer, pues que estas definiciones ideológicas en apariencia vagas o ingenuas se relacionan con un intento por llegar a un público amplio y diverso, pero también por una escasa conciencia política y formación intelectual como sí tenían sus antecesores.

Otro aspecto interesante para focalizarnos es el que se relaciona con ciertas opiniones de los curas villeros que además de ser conservadoras en lo social y cultural demuestran su lealtad absoluta a las posiciones asumidas por la jerarquía y por el Papa Francisco. Un ejemplo de esto se encuentra en sus posturas en los debates sobre la legalización de la marihuana. En esa oportunidad el "Padre Pepe" relató:

Fui a dar una charla a la UBA y les dije "muchachos, sean progresistas en serio", porque para un pibe de acá un porro no es nada, pero en la villa empiezan con el porro y siguen con el paco. Ese es un progresismo que en el fondo no es progresista, es un individualismo muy grande". (DI PAOLA, 2018)

Idéntica postura tuvieron los curas villeros apoyando la condena del cardenal Bergoglio a la aprobación de la Ley de Matrimonio Igualitario (2010). No obstante el ejemplo más contundente sobre las opiniones conservadoras y antimodernas de los curas villeros han sido las vertidas en ocasión de los debates sobre los proyectos de la ley de Interrupción Voluntaria del Embarazo (IVE), tanto en 2018 como en 2020, cuando finalmente resultó aprobada. En ambas ocasiones el "Padre Pepe" declaró ante los medios que la intención de instaurar el aborto era compatible con los intereses de una clase burguesas en consonancia con "intereses capitalistas mundiales" y en contra del pueblo, especialmente del pueblo pobre "que defiende la vida". En forma llamativa y propia de una lectura conspirativa, trazaba una supuesta relación del proyecto IVE con los programas de ajuste del Banco Mundial y del Fondo Monetario Internacional, exigida a los países periféricos. Sin suda resuena en esto no solo la misma lectura del Papa Francisco, sino también de Rafael Tello (TP), quien planteaba el enfrentamiento nación/imperio; elites ilustradas/pueblo. Además de esta postura formulada en clave más clasista y anticapitalista que lo acostumbrado, el "Padre Pepe" también cuestionó la forma representativa de la democracia. Si en 2018 se quejaba de que la legalización del aborto se pusiera en discusión cuando ninguno de los 
grandes partidos la había llevado como propuesta en su plataforma, en 2020 seguía lamentándose, pero ahora con un argumento ad hoc. Alberto Fernández había llevado la legalización del aborto como propuesta de campaña, pero eso no era suficiente:

[...] sería interesante que el presidente nos diga ante quién se comprometió. Ante el pueblo seguramente no, ante el pueblo de las villas, menos, y ante el pueblo del interior de las provincias, tampoco. (DI PAOLA, 2020).

Otra vez, la apelación al pueblo, entendido de manera homogénea y esencialista y asociado a la idea de "nación católica”. Por último, pensamos que el tema del aborto desnuda asimismo un retraso a nivel teórico como histórico con relación a las reivindicaciones del movimiento de mujeres y las diversidades y disidencias sexuales. Los derechos sexuales y reproductivos contemplados por las agendas públicas de los sucesivos gobiernos argentinos, la implementación de la ley de Educación Sexual Integral (ESI) en las escuelas no se corresponde con la aspiración de la Iglesia Católica de mantener el control sobre los cuerpos de las mujeres y a rechazar lo que definen como la “ideología de género". En este aspecto, los curas villeros sostienen una posición tradicionalista y su concepto de familia también responde a una concepción que no da cuenta de las múltiples posibilidades de relaciones parentales que van más allá del modelo patriarcal heteronormativo.

\section{Consideraciones finales}

Nos propusimos en este artículo realizar un recorrido de carácter histórico para explicar el nexo entre los curas villeros actuales y los curas tercermundistas de los años 1970, que fueron quienes inauguraron la presencia en las villas miseria de la Ciudad de Buenos Aires hacia 1969. En esta trama compleja de continuidades y rupturas, sobresale una figura excepcional que es la de quien fuera arzobispo y cardenal Jorge Bergoglio, devenido Papa Francisco a partir de marzo de 2013. En efecto, fue Bergoglio quien potenció el protagonismo de los curas villeros -a partir de 1998-, dotándolos de un reconocimiento institucional como nunca antes habían tenido, además de crecer numéricamente y en cuanto a su vinculación personal con este colectivo, elevándolo al rango de Vicaría para 
la Pastoral en Villas de Emergencia desde 2009 y actualmente a cargo de monseñor Gustavo Carrara, ordenado obispo en 2017.

La pastoral de las villas que cobró fuerza con Bergoglio está unida a su valoración positiva de la piedad popular, una iniciativa que trasladó al Documento de Aparecida de 2007 al encabezar la comisión redactora del texto final de la asamblea de los obispos latinoamericanos y que se expresa en sintonía con la intención de "poner la Iglesia en la calle" como uno de los mayores desafíos de la pastoral urbana en los albores del siglo XXI, que se propuso la Arquidiócesis de Buenos Aires en los último años. Esto se relaciona con la idea de una Iglesia en salida hacia las "periferias sociales y existenciales", como planteara también Francisco hacia el comienzo de su pontificado. Por ejemplo, la visita que realizara el Papa en el primer Jueves Santo al Instituto Penal para Menores de Casal del Marmo, en Roma, donde lavó los pies de 12 jóvenes reclusos era una práctica habitual durante su ministerio como arzobispo de Buenos Aires. Lo hacía alternativamente en una villa miseria, una cárcel, un geriátrico, una maternidad, etc. No se trataba de gestos aislados, sino de una sostenida acción pastoral que destinó sacerdotes y recursos para atender a los desposeídos porque BergoglioFrancisco siempre priorizó la Pastoral Popular con la que se había ido familiarizando durante su formación jesuítica en el Colegio Máximo de San Miguel, donde algunos destacados profesores, como Juan Carlos Scannone, eran también exponentes de la TP . Por otro lado, porque si bien la práctica pastoral de los curas villeros fue más acotada cabe destacar -como ya dijéramos- que estos sacerdotes circularon por diferentes ámbitos de sociabilidad, que incluyeron a las clases medias urbanas y universitarias de adscripción católica, quienes empatizaron fuertemente con la renovación litúrgica, las homilías comprometidas y el acercamiento al mundo de la cultura popular y, por ende, de los pobres, como parecía proponer el Concilio Vaticano $\|$ y el contexto histórico latinoamericano. Esto nos llevaría a evaluar otra arista, que no es el objetivo de este artículo, en cuanto a los alcances de los postulados de la “constelación tercermundista”. Lo cierto, y por paradójico que esto pudiera

\footnotetext{
Acerca de la influencia de la TP sobre el Papa Francisco desde una perspectiva favorable a esta teología puede consultarse el artículo Omar César Albado (2018).
} 
parecer, el linaje creyente de la tradición tercermundista en principio acallado por la persecución política sufrida durante la dictadura cívico-militar iniciada en 1976, no solo no fue sepultado, sino que pervivió en las redes de solidaridad del catolicismo liberacionistas a nivel latinoamericano durante los años 1970 y mediados de los 1980, la creación de organismos de DDHH de inspiración ecuménica y en los sobrevivientes de la represión que se convirtieron en herederos de la memoria tercermundista. Aunque en este artículo no nos hemos referido a ellos, existe también desde mediados de los 1980 otro colectivo sacerdotal denominado Curas de la Opción Preferencial por los Pobres (COPP), que si bien se referencian en la memoria de los curas villeros de los 1970, tienen diferentes perspectivas teológicas, pastorales y políticas que los curas villeros del Papa Francisco, principalmente una mayor autonomía respecto de la jerarquía y no tuvieron nunca una relación estrecha con Bergoglio-Francisco del que suelen ser mucho más críticos.

Para finalizar, el fenómeno tal vez más sorprendente con respecto a la pervivencia del linaje creyente de la "constelación tercermundista", sea que el gran ausente de esta historia y cuya trayectoria eclesiástica tuvo un perfil bastante alejado de la TL, sea quien tanto en el caso argentino desde fines de los 1990, y en su pontificado desde 2013, se haya posicionado como un heredero y continuador privilegiado de esta corriente teológica y eclesial que suscitara tanta controversia desde sus orígenes y hasta el presente. Bergoglio-Francisco no puede ser comprendido sin auscultar la cultura política argentina donde el peronismo ha sido un movimiento social y político de corte populista ${ }^{8}$. Por eso, aun cuando en la actualidad el Papa Francisco continúe sus gestos de acercamiento con antiguos referentes de la TL y sus postulados, lo hace en un contexto por cierto muy diferente al de los años 1970, donde el fantasma del comunismo ya no existe y donde por el contrario tanto la Iglesia Católica institución como él mismo resultan beneficiados por una narrativa reconfigurada donde los mártires liberacionistas incorporados al panteón de la Iglesia oficial han sido desprovistos de su ribetes contestatarios e ideales emancipatorios. Basta confrontar el rumbo de la Compañía de Jesús a fines de los años 1970 en

${ }^{8}$ Coincido en gran medida con la visión que plantea el historiador italiano Loris Zanatta (2016). 
la Argentina cuando Bergoglio fue su Provincial y lo que estaba sucediendo en otras partes de América Latina, donde los jesuitas asumieron la "opción preferencial por los pobres" y estaban más a tono con la impronta del General de la Compañía, Padre Pedro Arrupe, para eliminar del todo la creencia de que Bergoglio fue alguna vez un católico progresista.

La TP, vertiente argentina de la TL, es el común denominador en el que se ancló Bergoglio-Francisco para trazar un trayecto más o menos armonioso entre los curas villeros que integraron el MSTM y los curas villeros actuales, y también para proyectarse globalmente como un papa con sensibilidad social hacia los excluidos, pero subestimando los valores de la democracia liberal y nuevas lecturas sobre el lugar de lo religioso en las sociedades actuales. Si en el escenario actual sobresalen diferentes tipos de liderazgos populistas, no dudemos de que el Papa Francisco se inscribe en alguno de ellos.

\section{Referencias}

ALBADO, Omar César. La teología del pueblo: su contexto latinoamericano y su influencia en el papa Francisco. Revista de Cultura Teológica, Buenos Aires, año XXVI, n. 91, p. 31-57, 2018.

ARGENTO, Analía. Alberto Fernández visitó a los curas villeros y les prometió trabajar juntos para combatir el hambre y la droga. Infobae. [S.l.], 2019.

Disponible en: https://www.infobae.com/politica/2019/09/17/alberto-fernandezvisito-a-los-curas-villeros-y-les-prometio-trabajar-juntos-para-combatir-elhambre-y-la-droga/. Acceso: 12 junio 2020.

ASSMANN, Hugo. Teología desde la praxis de la liberación: ensayo teológico desde la América dependiente. Salamanca: Ediciones Sígueme: Ágora, 1973.

BOFF, Leonardo. Jesucristo, el liberador. ensayo de cristología crítica para nuestro tiempo. Santander: Editorial Sal Terrae, 1974.

DI MARCO, Laura. Iglesia y política: Curas Villeros: predicadores de la Teología del Pueblo. La Nación, [S.L.], 9 mayo 2010. Disponible en:

https://www.lanacion.com.ar/opinion/curas-villeros-predicadores-de-lateologia-del-pueblo-nid1262615/. Acceso: 15 mayo 2010.

DI PAOLA, Pepe (Padre). [Entrevista dada a] Luis Novaresio. A24com. [S.l.: s.n.], 2018. 1 vídeo (50 min). Disponible en:

https://www.youtube.com/watch?v=PqyqwKqpJE8. Acceso: 9 enero 2019.

DI PAOLA, Pepe - reunión informativa por la ley IVE - 01-12-2020. [S.l.: s.n.], 
2020. 1 vídeo (11 min). Publicado pelo canal Honorable Cámara de Diputados de la Nación. Disponible en: https://www.youtube.com/watch?v=nd3Mqxlyqmc. Acceso: 4 diciembre 2020.

GONZÁLEZ, Marcelo. La reflexión teológica en Argentina, 1962-2004: apuntes para un mapa de sus relaciones y desafíos hacia el futuro. Córdoba: EDUCC, 2005.

GUTIÉRREZ, Gustavo. Teología de la liberación: perspectivas. Salamanca: Ediciones Sígueme, 1971.

LÖWY, Michael. Guerra de Dioses: religión y política en América Latina. Buenos Aires: Siglo XXI ediciones, 1999.

POLITI, Sebastián. Teología del pueblo: una propuesta argentina para Latinoamérica, 1967-1975. Buenos Aires: Guadalupe-Castañeda, 1992.

MANO a mano con el Padre "Pepe" Di Paola. [S.l.: s.n.], 2020. 1 vídeo (30 min). Publicado por el canal Jotax Digital. Disponible en:

https://www.youtube.com/watch?v=022pg6wuqus. Acceso: 19 dic. 2020.

MUGICA, Carlos. Peronismo y Cristianismo. Buenos Aires: Editorial Merlín, 1973.

PADRE Pepe Di Paola impecable : "hay una realidad que no se visibiliza". [S.l.: s.n.], 2020. 1 vídeo (10 min). Publicado pelo canal RADIO SUR. Disponible en: https://www.youtube.com/watch?v=eudj_TYzRpM. Acceso : 4 feb. 2021.

PREMAT, Silvina. Curas villeros: de Mugica al padre Pepe: historia de lucha y esperanza. Buenos Aires: Editorial Sudamericana, 2010.

REFLEXIONES sobre la urbanización y el respeto de la cultura villera. Curas villeros. [S.l.], 2007. Disponible en: https://curasvilleros.wordpress.com/ 2007/06/11/reflexiones-sobre-la-urbanizacion-y-el-respeto-por-la-culturavillera/. Acceso: 7 junio 2014.

Universidad Nacional de La Plata. Facultad de Humanidades y Ciencias de la Educación. En Memoria Académica. Disponible en:

http://www.memoria.fahce.unlp.edu.ar/tesis/te.1242/te.1242.pdf. Acceso: 22 mayo 2021.

SMITH, Christian. La teología de la liberación: radicalismo religioso y compromiso social. Barcelona: Editorial Paidós, 1994.

TOURIS, Claudia. Sociabilidades católicas post-conciliares: el caso de la constelación tercermundista en la Argentina (1966-1976). Revista internacional de Historia Política e Cultura Jurídica, Rio de Janeiro, v. 2, n. 3, p. 130-158, jan. 2010.

TOURIS, Claudia. Catolicismo popular e imaginario liberacionista en los años '70: el caso de las peregrinaciones villeras a Luján y el Movimiento Villero Peronista. In: FOGELMAN, Patricia; CEVA, Mariela; TOURIS, Claudia (orgs.). El 
culto mariano en Luján y San Nicolás: religiosidad e historia regional. Buenos Aires: Biblos, 2013. p. 67-97.

TOURIS, Claudia. Iglesia católica: dictaduras y derechos humanos en Brasil y Argentina en la tormenta de los años setenta. Anuario de Historia de América Latina (Jahrbuch für Geschichte Lateinamerikas: JbLA), [s.l.], n. 52, p. 315-339, 2015. Dossier: Violencia Física e Iglesia en el siglo XX.

TOURIS, Claudia. La constelación tercermundista: catolicismo y cultura política en la Argentina (1955-1976). Buenos Aires: Biblos, 2021.

ZANATTA, Loris. Un papa populista. Criterio Digital, [S.l.], 2016. Disponible en: https://www.revistacriterio.com.ar/bloginst_new/2016/04/01/un-papa-populista2/. Acceso:14 sept. 2021. 